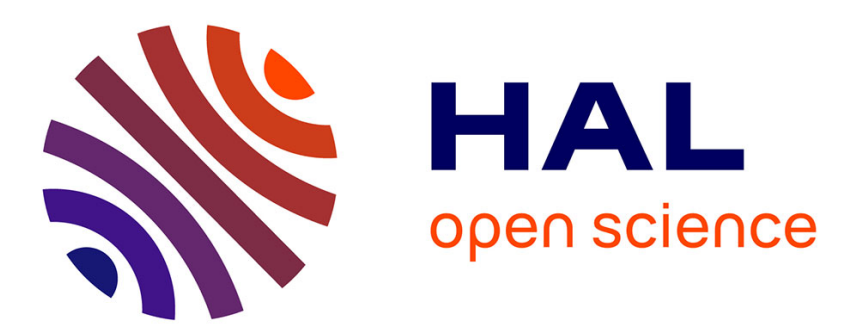

\title{
Constrained viscoelastic damping, test/analysis correlation on an aircraft engine
}

Etienne Balmès, Mathieu Corus, Baumhauer Stephane, Pierrick Jean, Jean

Pierre Lombard

\section{- To cite this version:}

Etienne Balmès, Mathieu Corus, Baumhauer Stephane, Pierrick Jean, Jean Pierre Lombard. Constrained viscoelastic damping, test/analysis correlation on an aircraft engine. IMAC, Feb 2010, Jacksonville, United States. pp.75. hal-00457606

\section{HAL Id: hal-00457606 \\ https://hal.science/hal-00457606}

Submitted on 17 Feb 2010

HAL is a multi-disciplinary open access archive for the deposit and dissemination of scientific research documents, whether they are published or not. The documents may come from teaching and research institutions in France or abroad, or from public or private research centers.
L'archive ouverte pluridisciplinaire HAL, est destinée au dépôt et à la diffusion de documents scientifiques de niveau recherche, publiés ou non, émanant des établissements d'enseignement et de recherche français ou étrangers, des laboratoires publics ou privés. 


\title{
Constrained viscoelastic damping, test/analysis correlation on an aircraft engine
}

\author{
Etienne Balmes ${ }^{1,2}$, Mathieu Corus ${ }^{3}$, Stéphane Baumhauer ${ }^{4}$, Pierrick Jean ${ }^{4}$, Jean-Pierre Lombard ${ }^{4}$ \\ ${ }^{1}$ SDTools, ${ }^{2}$ Arts et Metiers ParisTech, ${ }^{3}$ Ecole Centrale Paris, ${ }^{3}$ SNECMA
}

\begin{abstract}
Constrained viscoelastic damping treatments are fairly common in many applications but have not been industrially applied to aerospace engines. New engine designs tend to use BLISK (integrally bladed disks) machined from a single part and thus showing less friction damping than earlier designs. Constrained viscoelastic treatments are considered as a possible technology to enhance damping. The paper presents results of a modal test performed in an environmental chamber to highlight temperature sensitivity effects which are characteristic of viscoelastic treatments. In a second part the computational methodology used for simulations is presented. Meshing, model reduction and post-treatment issues will be addressed. The significant challenge is this problem is the computation of accurate strain levels in the viscoelastic layer for a large model with different symmetry for the disk and the constraining layer. Test analysis correlation at various temperatures will be presented showing good correlation for both the overall levels and the prediction of the influence of temperature.
\end{abstract}

\section{INTRODUCTION}

In turbomachines have traditionally relied on friction in the blade roots to achieve sufficient damping levels in the rotors. With the extension of BLISK (integrally bladed disks) machined from a single part, interfaces between parts are now limited to stage connections and no longer induce sufficient damping. Friction joints remains the main damping treatment technology for BLISK, but has its limitations and trade-offs.
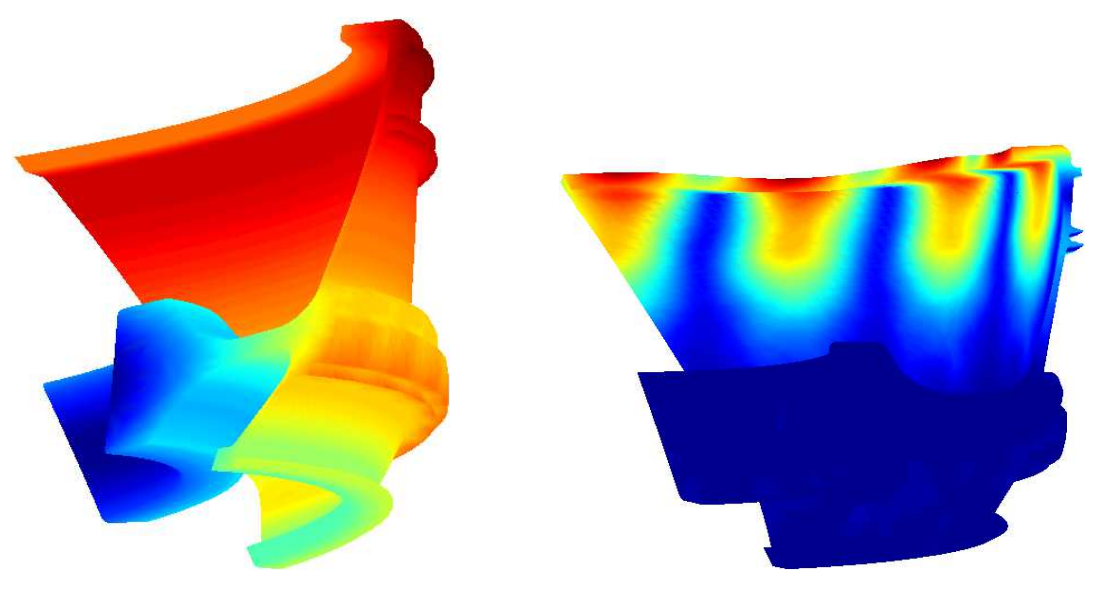

Figure 1: Sample modes with axial and tangential bending of the rim

Constrained viscoelastic treatments are well known to induce significant levels of damping ${ }^{[1,2]}$. They have been used in a wide range of industrial applications for decades. The principle proposed in ${ }^{[3]}$ is an adaptation of the concept using the flexibility of the inter-stage rims. Figure 1 shows radial deformation for two sample modes. It clearly appears that rim 
bending occurs in the axial direction (first mode shown) and/or tangential direction (second mode). Constrained layer damping can thus be considered as a damping mechanism.

The work presented here considers the base design shown in figure 2 The titanium BLISK has 36 blades and the carbon/epoxy constraining layer is cut in 4 segments. The two axial segments of the constraining layer correspond to developable surfaces, which eased manufacturing. The shaft thickness is close to $2 \mathrm{~mm}$, the constraining layer $1 \mathrm{~mm}$ and the viscoelastic material $0.2 \mathrm{~mm}$. The localization of the constraining layer within the main shaft, avoids any interaction with the air flow and imposes very little shear in the constrained layer thus limiting the risk of delamination. In this design, the shaft and constraining layer shapes were only optimized in thickness but other shape optimisation can clearly enhance performance.
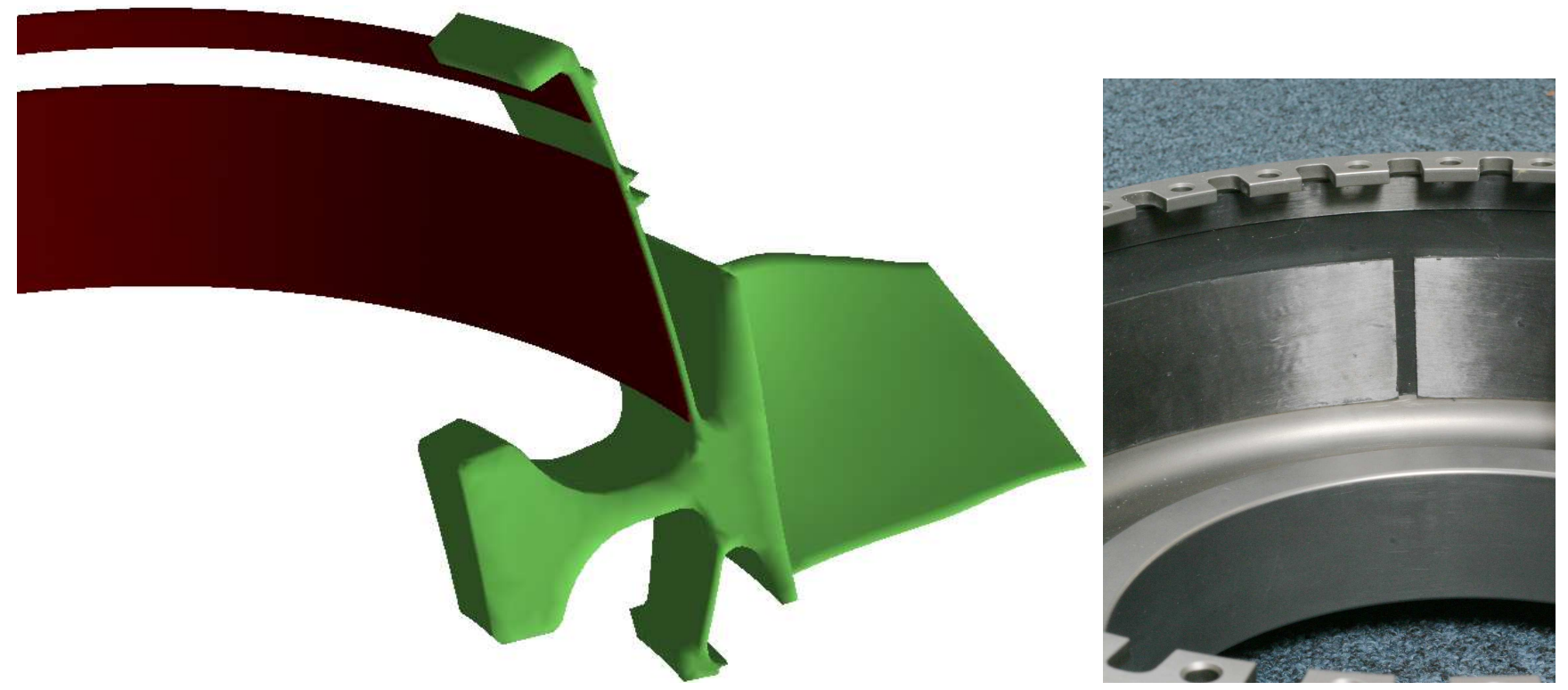

Figure 2: Sector of bladed disk, and sector of damping treatment

Section 1 discusses results of the experimental modal test that was performed at 3 temperatures to illustrate damping sensitivity to temperature. Section 2 presents the finite element model considered for simulations and briefly outlines computational methodologies needed to deal with a potentially huge problem: 950000 nodes, 220 modes and in the full model that needs to account for the frequency/temperature dependence of the viscoelastic material. The viscoelastic material, SMACTANE 50, was selected to demonstrate the design (but is not suitable for actual engine operation). Correct prediction of the drop in damping associated with temperature increase, shown in section 2.2 was used to validate the model. Throughout the paper, frequencies and damping ratio are shown in an adimensional unit system to preserve confidentiality of the prototype details.

\section{MODAL ANALYSIS OF A DEMONSTRATOR}

\subsection{Experimental setup and modal results}

Measurements were performed at Ecole Centrale Paris (MSSMat). Input loads were measured with a B\&K load cell and velocities with a Polytec vibrometer. Data acquisition was performed using an LDS Dactron portable analyser. Handling of measurements was performed using a prototype data acquisition environment based on the MATLAB and SDT [4] environment.

Tests were performed within an environmental chamber thus allowing a fairly precise control of the temperature. Temperature stabilization was obtained by waiting several hours and an automated procedure for measurement rejection during fan operation was introduced. In the future, automated measurement quality assessment would be very much needed to perform long acquisitions more reliably. 
Obtaining a clean input implied many attempts. The structure is very lightly damped and one seeks to excite a band of several $\mathrm{kHz}$. The configuration eventually retained, and shown in figure 3, is a load cell impact generated using a soft pulse in an electrodynamic shaker. The final configuration used a load cell aligned with the shaker axis, horizontal offsets allowed dynamic amplification but gave lesser quality measurements.

To avoid damping induced by exponential windows typically used for impact tests, the measurements were not windowed at all. This absence of windowing deteriorates estimated transfers away from resonances, so that identification should only be performed using data around resonances. Outside problems with the harmonics of $50 \mathrm{~Hz}$, measurements are rather clean at $25 \mathrm{C}$ and less so at other temperatures.
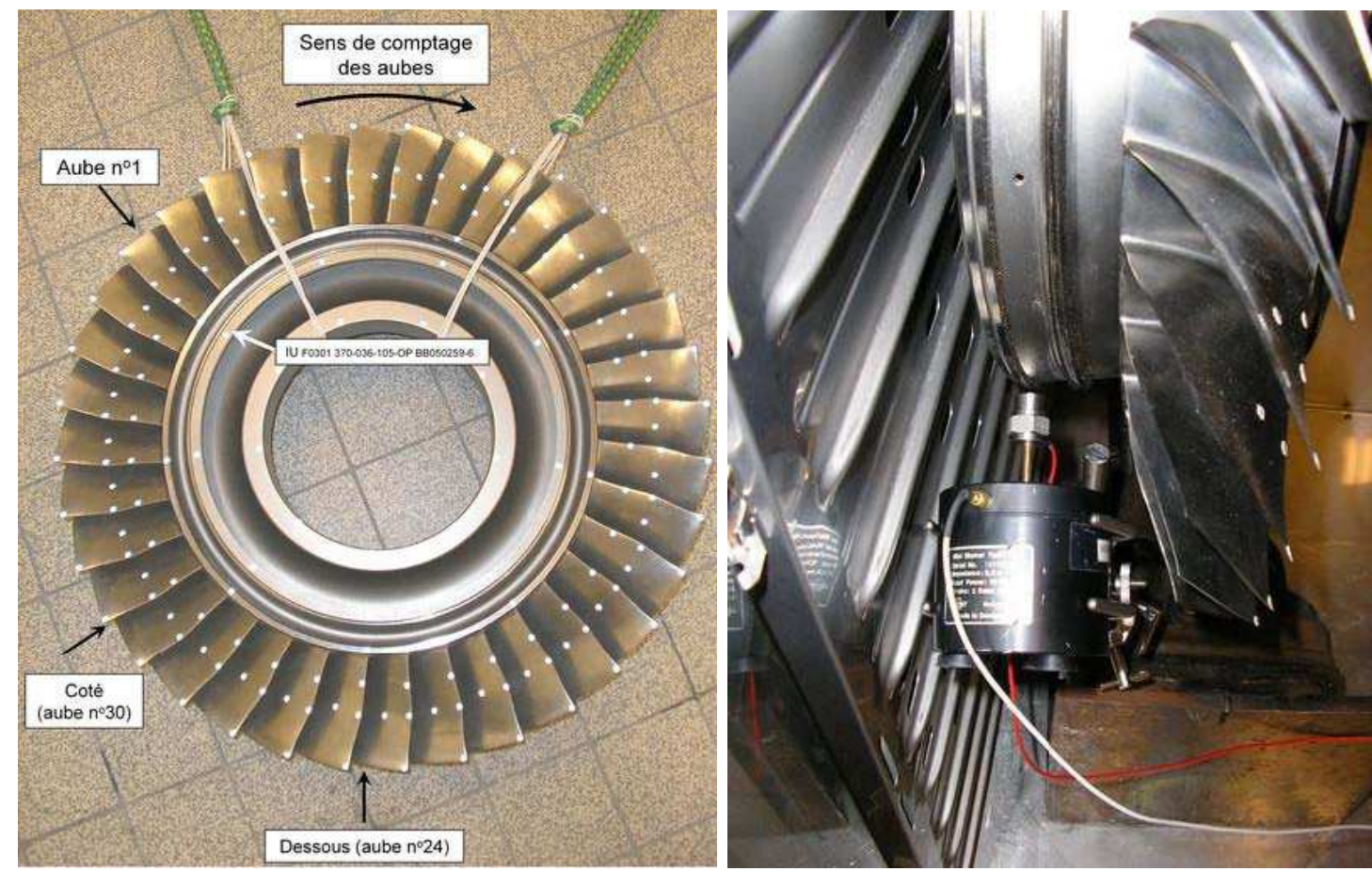

Figure 3: General view of measurement points. Excitations configuration \#1.

\subsection{Mode extraction}

In figure 4 , the complex mode indicator function of the overall test gives a very clear indication of the first five blade modes, visible trough the accumulation of resonances shown as vertical dotted lines in the plot. In those bands, the number of modes is very large (up to the number of blades, that is 36 ). 


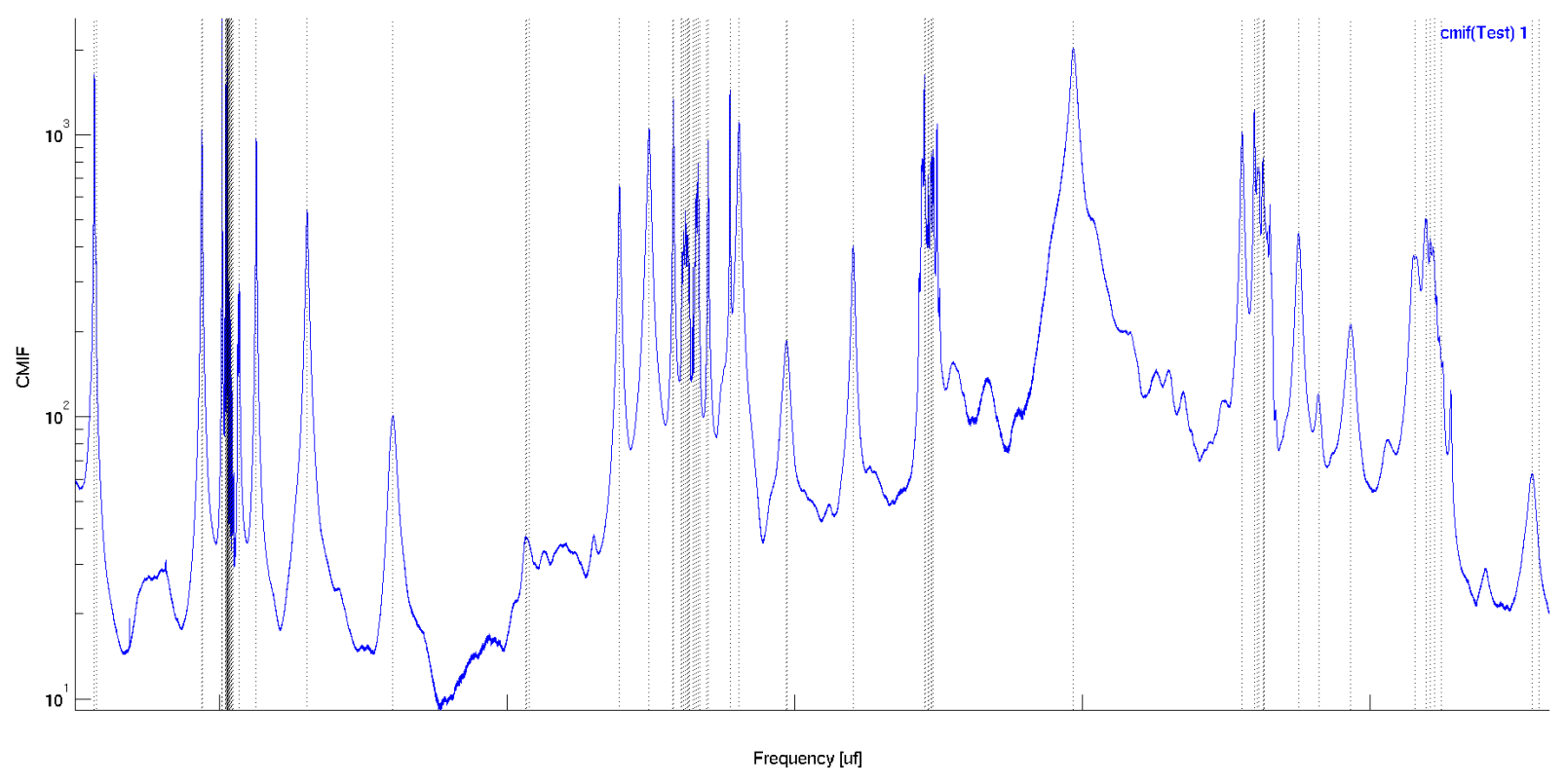

Figure 4: CMIF of test at 25C

The frequency resolution considered in the test was quite high (45 000 points), but this is still insufficient to properly separate all modes. Figure 5 eft thus shows two isolated modes (with frequencies indicated as vertical lines) at the beginning of accumulation and a large number of peaks with only a few properly identified. The associated damping estimates should thus be taken with caution. The existence of a consistent lower limit on damping within the accumulations seems however to correspond to the expected material damping (mostly due to thermoelastic effects in this case).
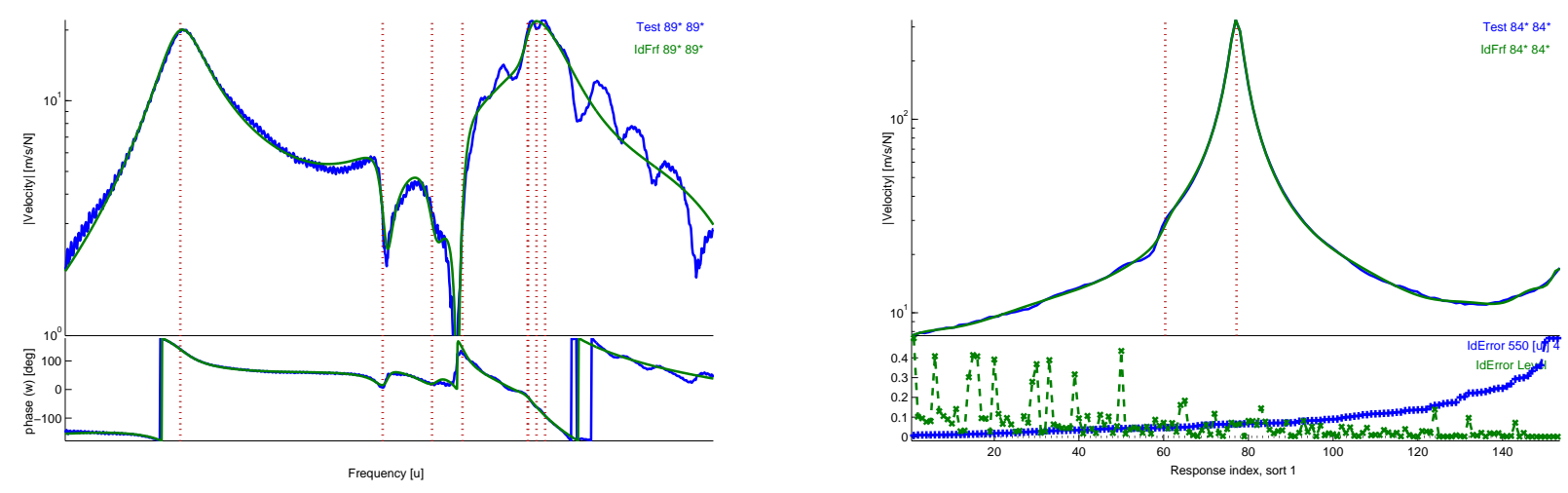

Figure 5: Sample transfers around a blade mode (left) and an isolated mode with split resonance.

For modes outside the accumulations, the identification is not necessarily much easier as most modes are nearly but not exactly double. The excitation configuration retained does favor 0 diameter modes, so that almost all the significant peaks correspond to double modes. Figure 5 ight illustrates a particular resonance, where careful inspection clearly shows two modes. The local relative error on the Nyquist ${ }^{[5]}$ shown at the bottom indicates a very accurate identification for which non-linear optimization of the pole locations ${ }^{[6]}$ was necessary.

Figure 6 displays a few global deformations. Figure 7 shows the influence of temperature on response levels. As expected for the selected material, performance drops very significantly as temperature increases. Measurement problems (changes in impact location laser direction due to sag of the suspension at higher temperatures) don't really allow proper quantitative 
comparison of transfers, the correlation will thus be based on predicted modal damping levels. Global damping results will be shown with FEM predictions in 2.2 .

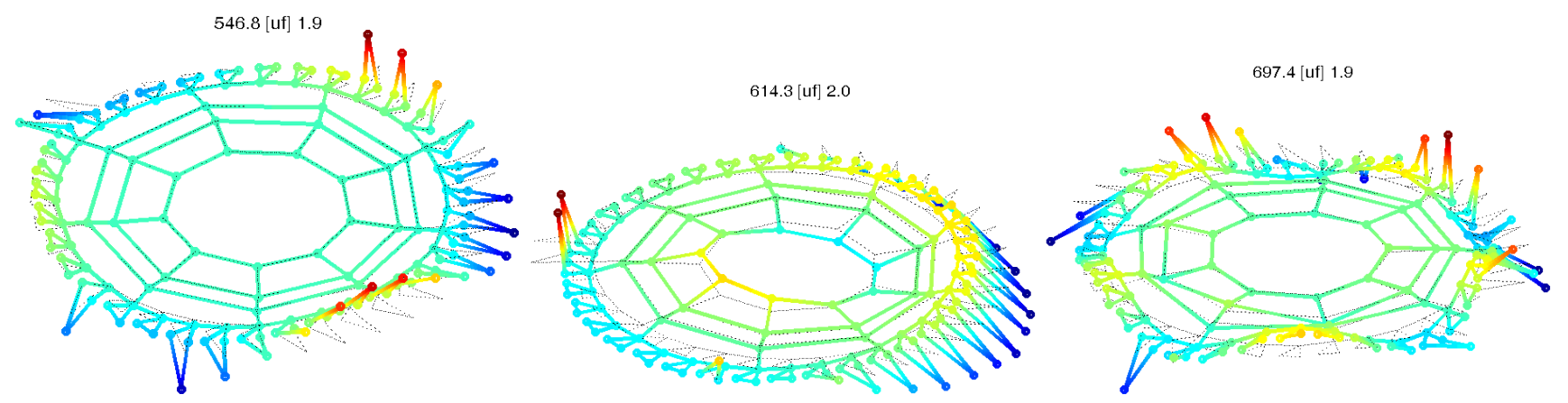

Figure 6: A few modal deformations.
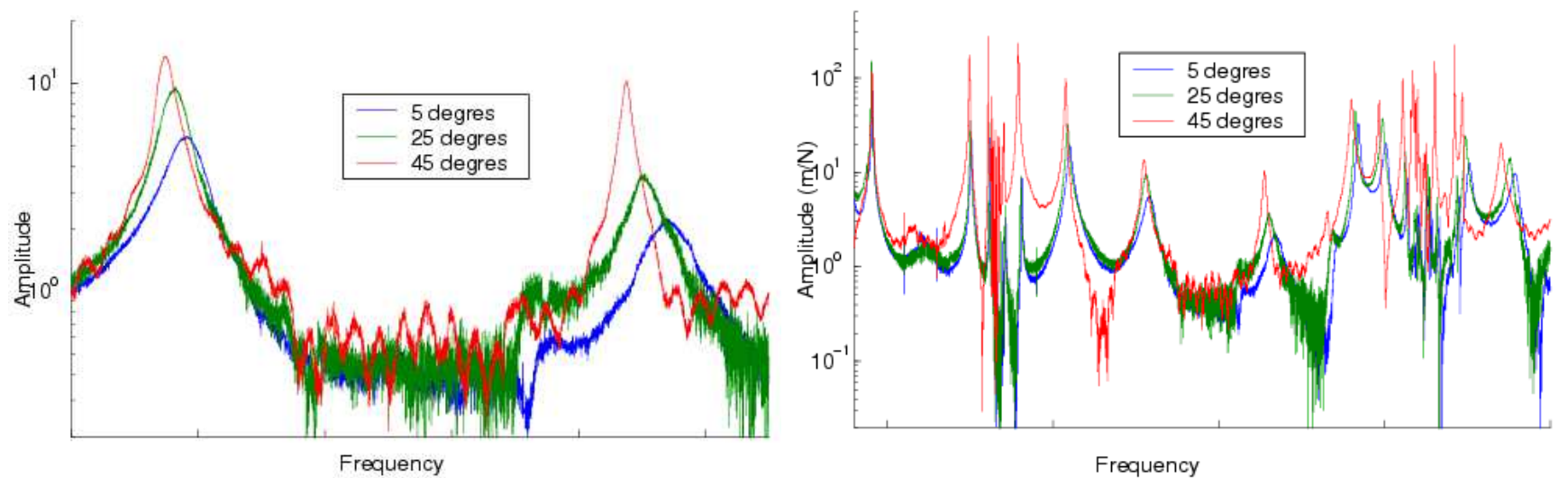

Figure 7: Blade tip response as a function of temperature. Full range and zoom

\section{MODEL AND CORRELATION}

\subsection{Modeling procedure}

The fundamental mechanism of constrained viscoelastic damping is shear in the constrained layer. To obtain such predictions the sheared layer must be modeled using volume elements. While for automotive applications a shell/volume/shell layup is classical ${ }^{[7,8]}$, typical engine models use volumes. The models considered in this project, thus introduce a volume mesh for each layer with linear or quadratic element formulations depending on the choice made for the main structural FEM.

To predict shear levels getting the geometry right is critical. In particular offsets with respect to the neutral fiber need to be precise. As the thickness of the layer can be very small $(0.2 \mathrm{~mm}$ here), the accuracy on node positions needed for proper predictions is much higher than typically found in FEM input files (often ten digits or less). This problem is illustrated in figure 8 where the initial mesh shows a significant fluctuation of energy at inter-sector boundaries and the corrected mesh does not (a slight variation to blade locations is expected and found). 

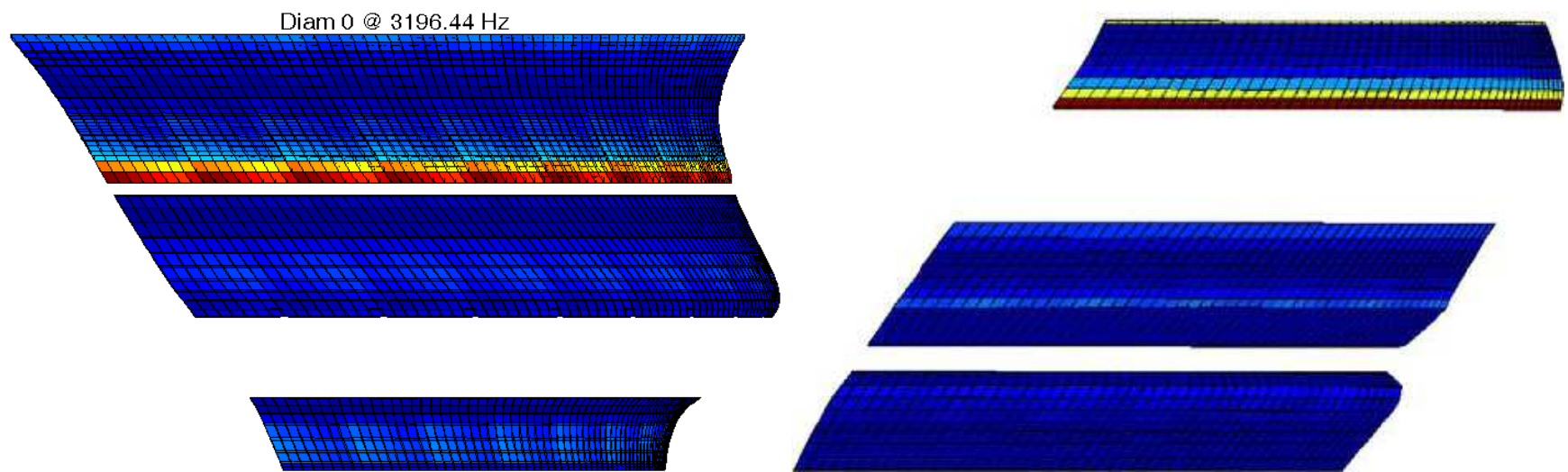

Figure 8: Variation in strain energy in the viscoelastic layer. Left : initial tetrahedral mesh, Right : corrected geometry with perfect revolution and hexahedral elements obtained by revolution. (The two different configurations shown differ from the prototype built)

When considering the actual geometry of tested structure, the BLISK has 36 blades while the constraining layer has four segments. The underlying full 3D model contains 950000 nodes and there are 224 modes in the bandwidth of interest. To obtain accurate predictions, one uses the multi-stage cyclic symmetry method introduced in ${ }^{[9,10]}$ and industrialized in the SDT Rotor ${ }^{[11]}$ module.

On first computes mono-harmonic solutions for target diameters. 0,1,2 and 8 diameter modes for high and low values of the viscoelastic modulus are first computed (each computation takes about $15 \mathrm{mn} C P U$ ). The resulting vector set contains 473 vectors in the bandwidth of interest. The iterative maximum sequence procedure is then used to generate bases for each of the 3 stages considered in the model (the base sector with 36 blades and 276 independent vectors, the lower and upper constraining layers with 4 segments and 90 and 42 vectors respectively).

From these reduced sector models, one can assemble a reduced 3D model with 34485 DOFs (of whom $80 \%$ are internal DOFs of the second order elements in the viscoelastic layer). Figure 9 illustrates typical restitution two modes. To get a feel of the displacement shape, a coarse outline of the shaft and blades is showing all blades. To analyze energy dissipation, strain energy density in the constrained viscoelastic layer is then displayed.
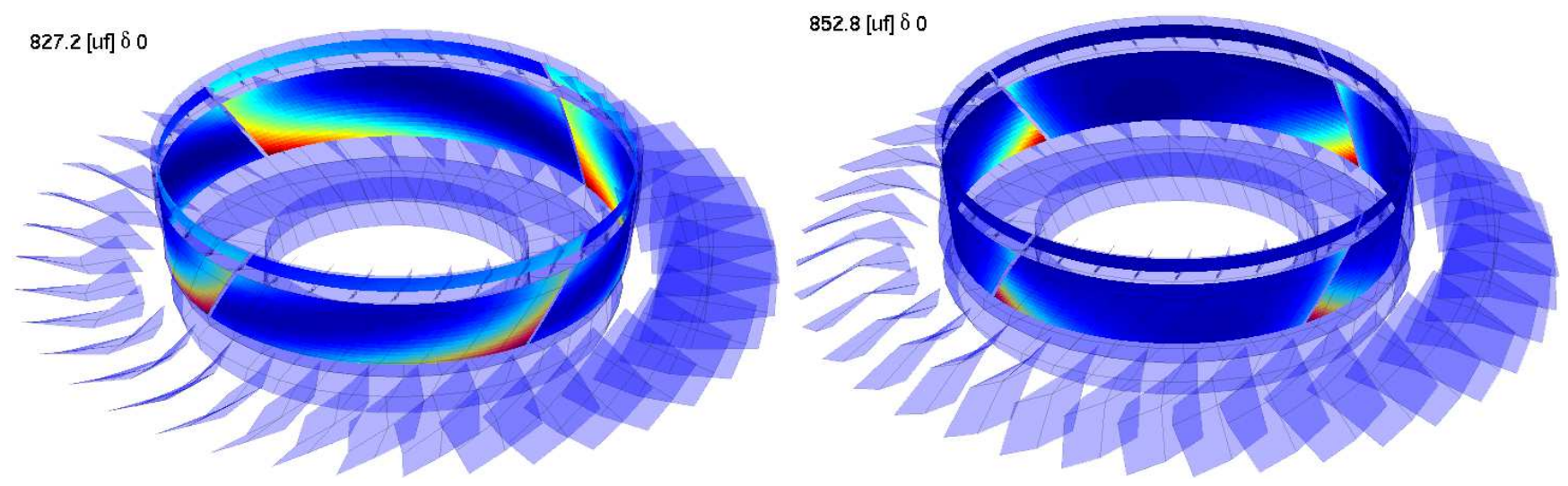

Figure 9: Displacement viewed on a coarse outline of the BLISK and strain energy in the viscoelastic layer. 
For correlation, one then needs to account for the frequency and temperature dependence of the material modulus and loss factor shown in figure10. To achieve such predictions in a reasonable time, a multi-model reduction approach, implemented in the SDT Visco module ${ }^{[8]}$, is used. 250 modes of the reduced shaft model are computed for low and high modulus values and the model is reduced on the associated subspace. Poles are then computed for a range of complex moduli and interpolation is used to give precise damping estimates.
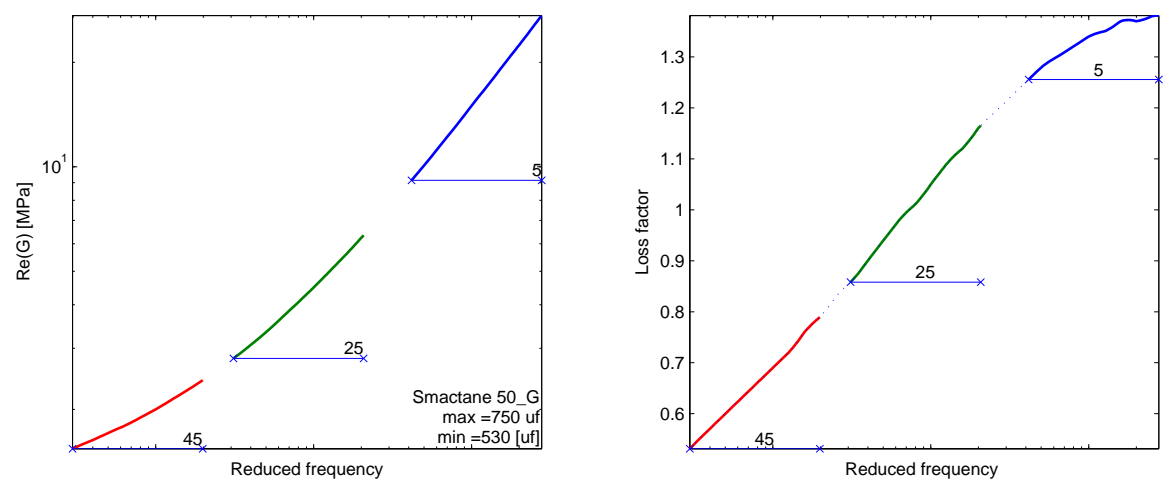

Figure 10: Modulus and loss factor variation for SMACTANE 50 in the target frequency range.

\subsection{Correlation of modal damping ratio}

Figure 11 shows, using the same scale, measured and predicted damping ratio as a function of temperature. Understanding the level of correlation requires significant comments.

The blade modes are clearly visible as drops in the damping levels (and vertical lines in the computation). In the model, titanium is taken to have no material damping at all, so predicted damping drops to extremely low levels as almost all the energy is concentrated in the blades. In the test, estimating damping for those modes is very difficult due to strong modal overlap. A low value near 0.3 damping units does however exist and is expected due to thermoelastic material damping.

Between the accumulations associated with blade modes, the shaft undergoes significant deformation and is thus damped by the constrained viscoelastic layer. Each correlation should be considered in detail. The first experimental mode (a 2 diameter global bending) underestimates damping. Damping for this mode is essentially located in the constrained layer just below the inter-stage rim. The model does not account for segmentation of the rim and is thus too stiff and lightly damped. In the 550 to 620 frequency unit range damping is under-predicted with no clear explanation. The first modes of the accumulation are extremely close in level. In the [630-670] range the coincidence is very good. In the 670 to 730 the test starts to pose problem with only the lightly damped modes showing (two more significantly damped modes could be found in the $25 \mathrm{C}$ test but not clearly at other temperatures). 

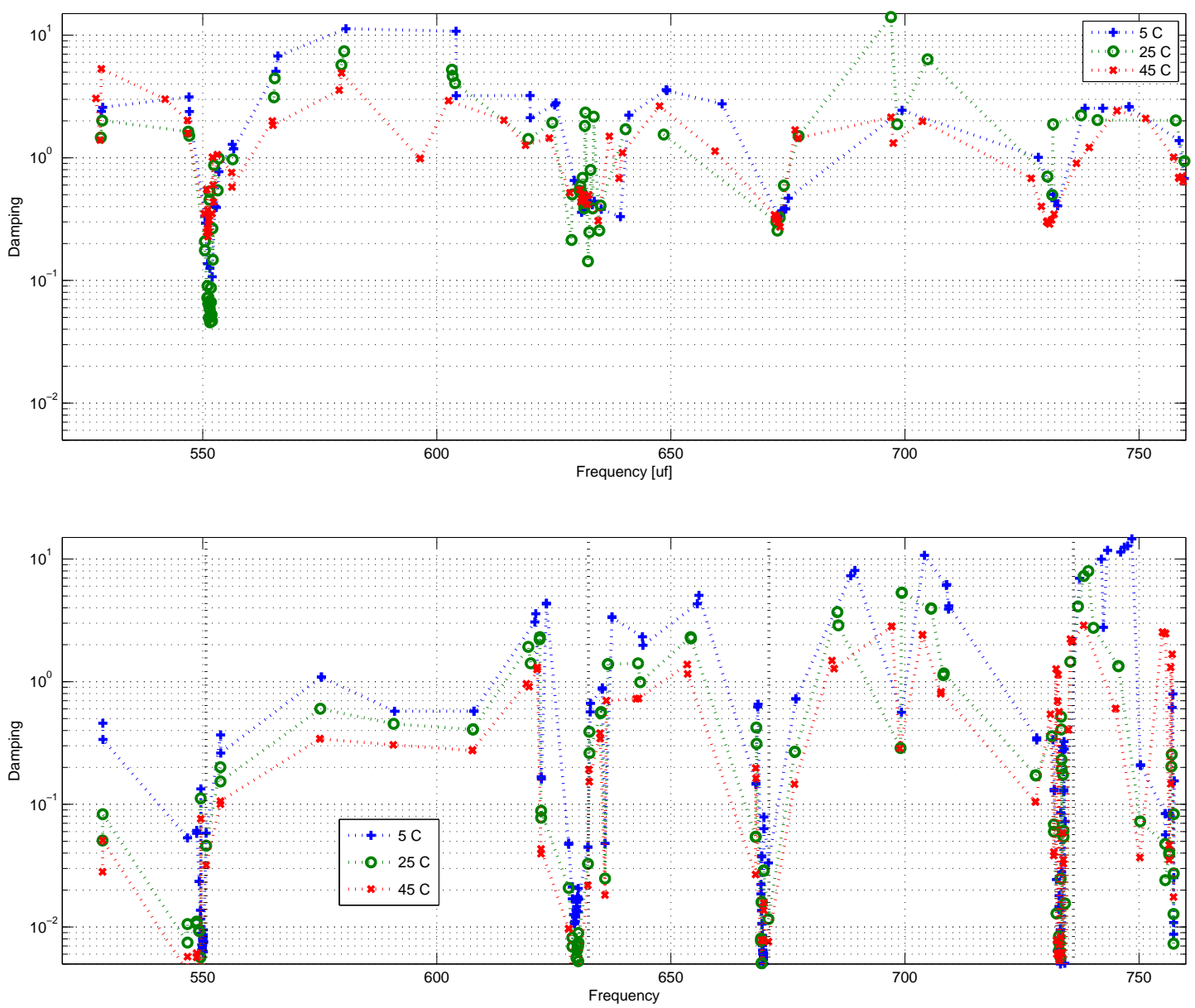

Figure 11: Experimental (top) and computed (bottom) frequencies and damping ratio at 5, 25 et $45 \mathrm{C}$

The sensitivity to temperature is very consistently predicted with the expected trend of performance decreasing with temperature.

\section{CONCLUSION}

A basic design of constrained viscoelastic treatment was tested on a BLISK. The results clearly show that, outside narrow accumulation frequencies corresponding to blade modes, damping is significantly enhanced by the treatment. Overall damping levels and trends when the viscoelastic material properties are affected by temperature correlate well between test and analysis. Current work on the concept focuses on selecting materials adapted to real engine temperatures, extending design methodologies to optimize treatments and demonstrations in operational conditions.

\section{REFERENCES}

[1] Nashif, A., Jones, D. and Henderson, J., Vibration Damping, John Wiley and Sons, 1985.

[2] Rao, M. D., Recent Applications of Viscoelastic Damping for Noise Control in Automobiles and Commercial Airplanes, Journal of Sound and Vibration, Vol. 262, No. 3, pp. 457-474, 2003.

[3] Dupeux, J., Baumhauer, S., Garcin, F., Lombard, J., Seinturier, E. and Balmes, E., Movable Impeller for a Turbojet and Turbojet comprising same., Patent EP2009238, US2009004021, 2009. 
[4] Balmes, E., Bianchi, J. and Leclère, J., Structural Dynamics Toolbox 6.2 (for use with MATLAB), SDTools, Paris, France, www.sdtools.com, May 2009.

[5] Balmes, E., Methods for vibration design and validation, Course notes Ecole Centrale Paris, 1997-2007.

[6] Balmes, E., Frequency domain identification of structural dynamics using the pole/residue parametrization, International Modal Analysis Conference, pp. 540-546, 1996.

[7] Plouin, A. and Balmes, E., A test validated model of plates with constrained viscoelastic materials, International Modal Analysis Conference, pp. 194-200, 1999.

[8] Balmes, E., Viscoelastic vibration toolbox, User Manual, SDTools, 2004-2007.

[9] Sternchüss, A. and Balmes, E. and Jean, P. and Lombard, JP., Reduction of Multistage disk models : application to an industrial rotor, Journal of Engineering for Gas Turbines and Power, Vol. 131, 2009.

[10] Sternchüss, A., Multi-level parametric reduced models of rotating bladed disk assemblies, Ph.D. thesis, Ecole Centrale de Paris, 2009.

[11] Balmes, E. and Bianchi, J., Rotor module for SDT, User Manual, SDTools, 2008-2009. 